\title{
Disparities in Regular Health Care UTILISATION IN EUROPE
}

Nicolas Sirven and Zeynep Or 


\title{
22 Disparities in Regular Health Care Utilisation in Europe
}

\author{
Nicolas Sirven and Zeynep Or
}

\subsection{Regular care use as a public health issue}

A standard doctor visit or routine check-up can be essential for maintaining good health. People who have regular checkups may identify health issues well before any symptoms show up and receive the treatment for reducing onset and complications. Many of the costly and disabling conditions can be prevented through early detection. Therefore, improving access to routine checkups is considered as an objective for the health care systems (WHO, 2002). For instance, women are advised to have regular gynaecological visits from an early age and mammography from 50 onwards. Major guidelines recommend periodic comprehensive evaluation of blood values and regular follow-up of blood pressure after a certain age (Mandel et al., 2000). Persons who have regular eye examinations may experience slower decline in vision and functional status (Ghodes et al., 2005).

Despite common recommendations and quasi universal health care coverage in all European countries, there are large differences in the utilization patterns of different health services. Even across countries with similar levels of GDP (Gross Domestic Product) per capita, the rate of using recommended services varies significantly. Moreover, there is a large body of work showing that in many countries the probabilities of seeing a doctor (and the number of visits) are not identically distributed across socio-economic groups after correcting for differences in the need for care. More specifically, a "pro-rich" bias in the use of specialist care is well demonstrated in Europe (Van Dorslaer et al., 2004; 2006). At the same time, studies show that the magnitude and direction of these inequalities vary significantly from one country to another (Hanratty et al., 2007). This may reflect different strategies for setting up and coordinating preventive and curative health care services. The level of available health resources and their organisation varies significantly across welfare states. However, the link between the organisation of health care resources and their long-term utilisation is not well understood.

In particular, little comparative information is available on different types of health service utilisation such as routine health check-ups and variations in utilisation patterns over a longer time span to compare the shift (if any) in healthcare habits of different generations. First, most studies examine the variations in care utilisation at one point in time since the usual datasets do not allow for analysing respondents' long term health care habits. Second, very few studies proposed a cross-country analysis of the disparities in different types of care utilisation. It remains unclear whether variations in health service utilisation are a generalized 
phenomenon, or whether these inequalities are observed only for some services, countries and demographic groups. Third, there is little information on the evolution of health care utilisation habits of different generations and the role of health care policies in determining these utilisation patterns.

SHARELIFE provides a unique source of internationally comparable information on individual's long-term health care utilisation patterns as well as their lifecourse social, economic, and health status. It is important to identify the patterns of regular care use within and between countries and analyse the determinants of use in order to improve health policies in welfare states. The objective of this study is twofold: first, it aims to compare and investigate the determinants of health care utilisation habits over the life span of individuals across European countries. Second, the study proposes an analysis of the impact of country-specific time related macroeconomic factors which characterize welfare states. In particular, we test the role of health sector development with respect to general economic growth in determining healthcare utilisation habits.

\subsection{Measuring healthcare utilisation habits}

SHARELIFE provides some original information on the health care consumption habits of individuals over their life course. In particular, respondents are asked whether or not they had regular health check-ups over the course of several years. For instance: "Have you ever had your blood pressure checked regularly over the course of several years?" This differs from the usual questions on health care consumption asking if the respondents had consumed health care over a specific period (usually over the past year). The respondents are asked if they have regular check-ups for six types of care. Santos-Eggimann et al. in Chapter 21 of this volume address the issue of dental check-ups over the life course, while we focused on the five other types of care: blood pressure, blood tests, vision tests, and (for women only) gynaecological visits and mammograms. Our dependent variables are binary taking the value 1 if the respondent ever had regular health check-ups and 0 otherwise. In the descriptive analysis, the variable "age when regular health care started" is also taken into account; but this variable is not used as dependant variable in this chapter. Additional variables retained in the multivariate analysis are described below.

The information provided in SHARELIFE allows comparing the consumption patterns of different generations. In order to examine the change in healthcare utilisation patterns, we have constructed three cohorts observing the age distribution of respondents in our sample: Cohort 1 consists of people who were born between 1925 and 1934, Cohort 2 consists of those who were born between 1935 and 1944 and Cohort 3 corresponds to those born after 1945.

This data is complemented by the information collected in SHARE wave 1 (2004-05) and 2 (2006-07) providing data on the current life circumstances of in- 
dividuals aged 50 and over in 15 European countries. The sample used in this study was restricted to respondents (i) who were interviewed in at least one of the first two waves, and re-interviewed in SHARELIFE; and (ii) whose understanding of questions asked in SHARELIFE was satisfying (442 cases were deleted, 1.6\% of the initial sample). The final sample includes 22251 respondents ( $96 \%$ of the initial sample) from 13 countries covering four Euro-regions: North (Sweden, Denmark, the Netherlands), East (Czech Republic, Poland), Continental (Belgium, Germany, Austria, France, Switzerland), and South (Spain, Italy, Greece) of which 12,128 women.

At the individual level, we have information on both the initial and current life circumstances which might have a direct or indirect impact on individuals' care consumption habits. Moreover, we can control for general respondents characteristics: gender, age, having children and current and lifetime health status as natural determinants of care utilisation. The health status is assessed by the following variables:

- Current self-rated health (SRH): a dummy taking the value 1 if the respondents perceive her health as excellent or very good at wave 3 , and 0 otherwise;

- Chronic conditions: a dummy taking the value 1 if the respondent reports 2 or more chronic illnesses (cancer, diabetes, etc.) at wave 1 or wave 2 , and 0 otherwise;

- $\quad$ SRH at 10 years old: self-rated retrospective value of health, taking the value 1 if the respondent reports that health during childhood was in general excellent or very good, and 0 else (i.e. good, fair, or poor, or spontaneously "Health varied a great deal");

- Periods of ill health or Ever physically injured: a binary index of health, taking the value 1 if the respondent reports any periods of ill health over the life-cycle (>1 year) or if she reports any physical injury over the lifecycle (>1 year);

- For vision tests only: (i) whether or not the respondents wear glasses, (ii) a dummy taking the value 1 if the respondent declares her eyesight for seeing things at a distance (like recognising a friend across the street) is excellent or very good, and 0 otherwise.

In order to capture the socio-economic conditions of the individuals we used the following:

- Labour market situation: (i) A dummy indicating if the respondent ever worked, and (ii) a dummy taking the value 1 if the respondent is still at work at wave 3 , and 0 otherwise;

- A comfort index made out of 6 items (whether or not the household's accommodation had the following when the respondent was ten years old: fixed bath, cold running water supply, hot running water supply, inside toilet, central heating, and whether or not there was a room by person) taking theoretical values between 0 (none of them) and 6 (all of the items); 
- A dummy indicating if the respondent encountered any periods of Financial Hardship throughout her life;

- Assets at interview time (cross sections of three waves): the average amount of assets in Euros the respondent reports over the first two waves of SHARE. We use assets instead of last-year income, since this variable is a better indicator of economic well-being of individuals over the life course. Total assets have a smoother evolution over the life course and they discriminate better than yearly incomes which become less informative after a certain age (due to retirement and common pension schemes);

- Education: highest level of education completed (in three categories: none or primary, secondary, and tertiary);

- A set of country by cohort dummies were included in the models.

At the country level, we are interested in the role of economic development versus healthcare system in determining healthcare utilisation habits. Four variables were considered at the country level: (i) GDP per capita, (ii) Total health expenditure per capita, (iii) Public expenditures on health, and (iv) the density of practicing physicians. Country-specific time series are constructed using several editions of the OECD Health database covering the period 1975-2005. For the purposes of the regression analysis, each series is divided into three sub-periods corresponding to the economic development and health care provision for three cohorts of individuals aged in their 50s. Thus, for Cohort 1, we measure economic growth and health care supply for the period 1975-1985, for Cohort 2 the period is 1985-1995 and for Cohort 3 it is 1995-2005. For each indicator we calculated (i) the average volume/level over 10 years, (ii) the mean average annual growth rate over 10 years, and (iii) Total growth rate over 10 years.

\subsection{Regular Health Care Use at a Glance}

Significant differences in regular health care utilisation are observed across countries and gender (Table 22.1) and across different age groups. Figure $22.1 \mathrm{com}-$ pares the share of population having regular check-ups by age, in four country groups. Northern countries (Sweden, Denmark and the Netherlands) have lower rates of regular health check-ups for all indicators except for mammography for which the rates are significantly higher than all other countries. Southern countries (Spain, Italy, Greece) followed by the continental Europe have systematically higher check-up rates for blood tests, blood pressure tests, vision tests and gynaecological visits. The prevalence of regular health care check-ups seems to increase with age in the case of blood tests and blood pressure tests. This could be explained by the decline in health status by age. These tests become more frequent as health status deteriorates. But, no cohort or age effect is found in the case of vision tests, which is surprising as often vision deteriorates after 50 years old. As expected, the prevalence of regular gynaecological visits and mammograms is 
higher for younger cohorts. It is interesting to note that the rate of regular mammogram use for the first cohort (oldest generation) in Northern countries is even higher than for the second cohort in all other countries which suggests that this specific preventive policy have been effectively adopted in these countries since the middle of the last century.

Table 22.1: $\quad$ Population having ever had regular health check-ups, by gender, in $\%$

\begin{tabular}{|c|c|c|c|c|c|c|c|c|}
\hline & \multicolumn{2}{|c|}{ Blood tests } & \multicolumn{2}{|c|}{$\begin{array}{c}\text { Blood } \\
\text { pressure tests }\end{array}$} & \multicolumn{2}{|c|}{ Vision tests } & \multirow{2}{*}{$\begin{array}{r}\begin{array}{r}\text { Gynaeco. } \\
\text { tests }\end{array} \\
\begin{array}{r}\text { Women } \\
\text { only }\end{array}\end{array}$} & \multirow{2}{*}{$\begin{array}{r}\text { Mammo- } \\
\text { grams } \\
\begin{array}{r}\text { Women } \\
\text { only }\end{array}\end{array}$} \\
\hline Country & Women & Men & Women & Men & Women & Men & & \\
\hline Austria & 72.0 & 68.7 & 63.2 & 61.7 & 77.9 & 64.9 & 74.9 & 66.1 \\
\hline Germany & 69.4 & 69.9 & 65.1 & 61.3 & 71.4 & 66.8 & 78.9 & 45.9 \\
\hline Sweden & 41.4 & 52.7 & 54.6 & 61.7 & 50.5 & 44.3 & 81.7 & 88.9 \\
\hline Netherlands & 51.8 & 53.0 & 62.7 & 61.6 & 63.4 & 57.1 & 47.9 & 83.1 \\
\hline Spain & 85.4 & 82.8 & 81.9 & 73.7 & 70.0 & 64.7 & 59.8 & 68.5 \\
\hline Italy & 80.8 & 79.0 & 75.7 & 75.8 & 59.3 & 52.4 & 57.3 & 57.7 \\
\hline France & 78.9 & 77.0 & 87.3 & 88.5 & 84.8 & 82.3 & 71.9 & 75.2 \\
\hline Denmark & 50.7 & 51.9 & 47.4 & 51.2 & 47.8 & 38.0 & 56.8 & 32.8 \\
\hline Greece & 89.5 & 85.3 & 82.7 & 80.8 & 74.6 & 67.2 & 69.4 & 46.4 \\
\hline Switzerland & 60.9 & 65.2 & 69.6 & 65.8 & 69.8 & 64.0 & 75.2 & 48.4 \\
\hline Belgium & 83.3 & 84.4 & 84.6 & 84.6 & 76.7 & 71.7 & 69.9 & 71.6 \\
\hline Czechia & 48.5 & 53.9 & 60.1 & 63.3 & 67.4 & 57.3 & 86.0 & 62.3 \\
\hline Poland & 58.0 & 52.4 & 68.7 & 58.2 & 56.0 & 44.6 & 51.5 & 38.4 \\
\hline Total & 72.3 & 71.6 & 73.1 & 70.8 & 68.8 & 63 & 67.1 & 58.6 \\
\hline
\end{tabular}

Note: Calibrated individual weights used.

Figure 22.1: $\quad$ Population having regular health check-ups, frequencies by Euro-regions and age-class 

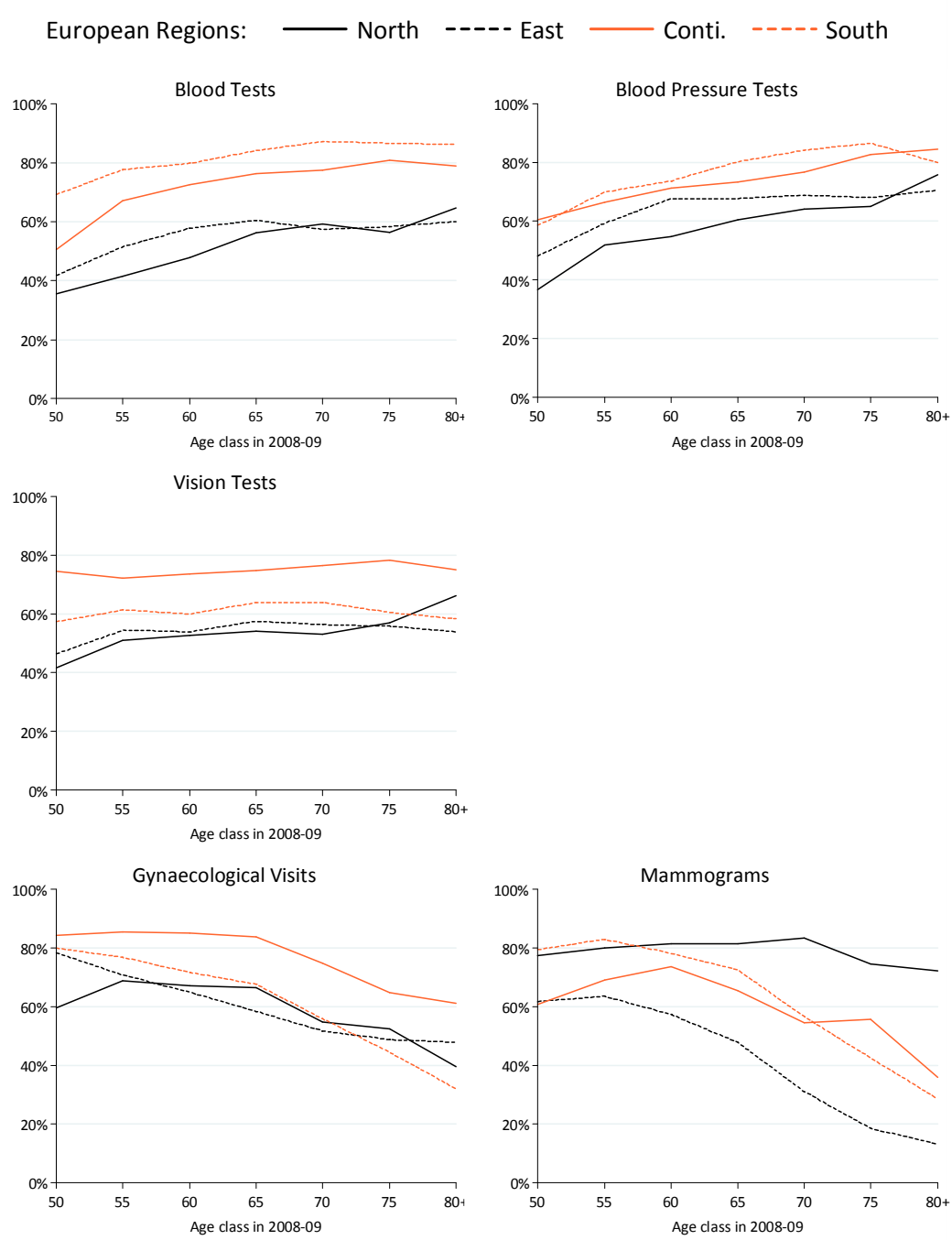

Source: SHARELIFE (2008-2009). Calibrated individual weights used.

Additional information on the health care utilisation habits provides useful insights. Figure 22.2 demonstrates the shift in health care utilisation behaviour for three cohorts. It shows that (i) the mean age for starting regular health check-ups is decreasing at each new cohort (except for mammography), and (ii) the prevalence/use of regular health check-ups increases at each new cohort. For example, the age of starting regular check-ups for blood pressure has been dropped from after 70 years old for the first cohort (born between 1925 and 1935) to around 50 for the third cohort (born between 1945-1955). It is also interesting to note that for the 
later cohorts there is a little "peak" around 20 years old concerning blood tests, blood pressure and vision tests, suggesting that new cohorts (especially post-war ones) may have benefitted from prevention policies at an early age. Regular gynaecological visits and mammograms follow a somehow different pattern since the period of start for these tests is age-specific: around 20 years old for the former (child bearing age) and around 50 years old for the latter. Therefore, no significant shift in starting age was expected. Nonetheless, there is a visible upward shift in the prevalence of women having regular gynaecological visits and mammograms at each new cohort. Such differences suggest a significant change over the past 40 years in health care consumption habits of European populations which might partly explain improving health outcomes.

Figure 22.2: Age at the start of regular health check-ups 

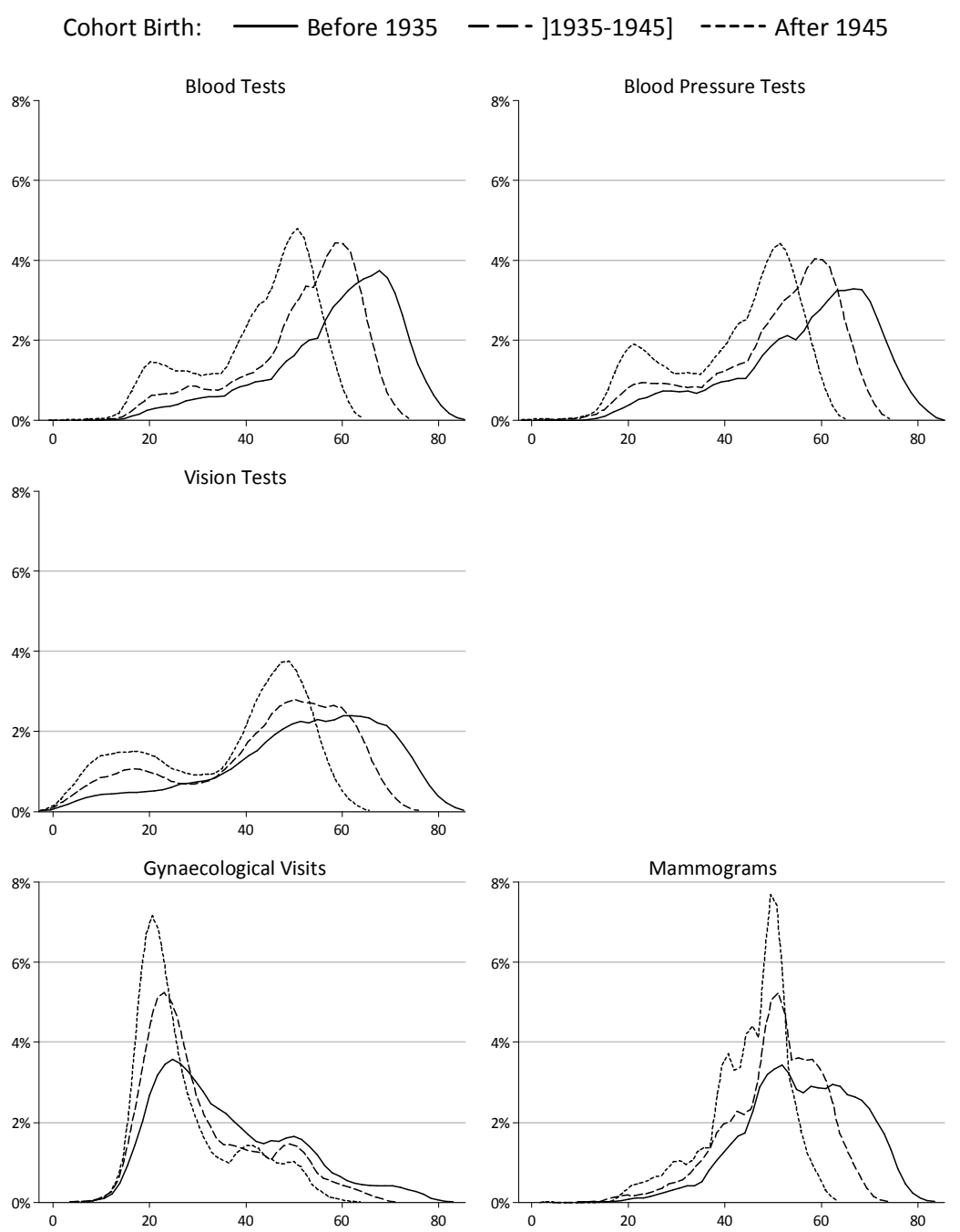

Source: SHARELIFE (2008-2009). Calibrated individual weights used.

Figure 22.3: Reasons given for non-regular health check-ups, frequencies by Euro-regions and cohort of birth 
Not considered to be necessary Other reasons
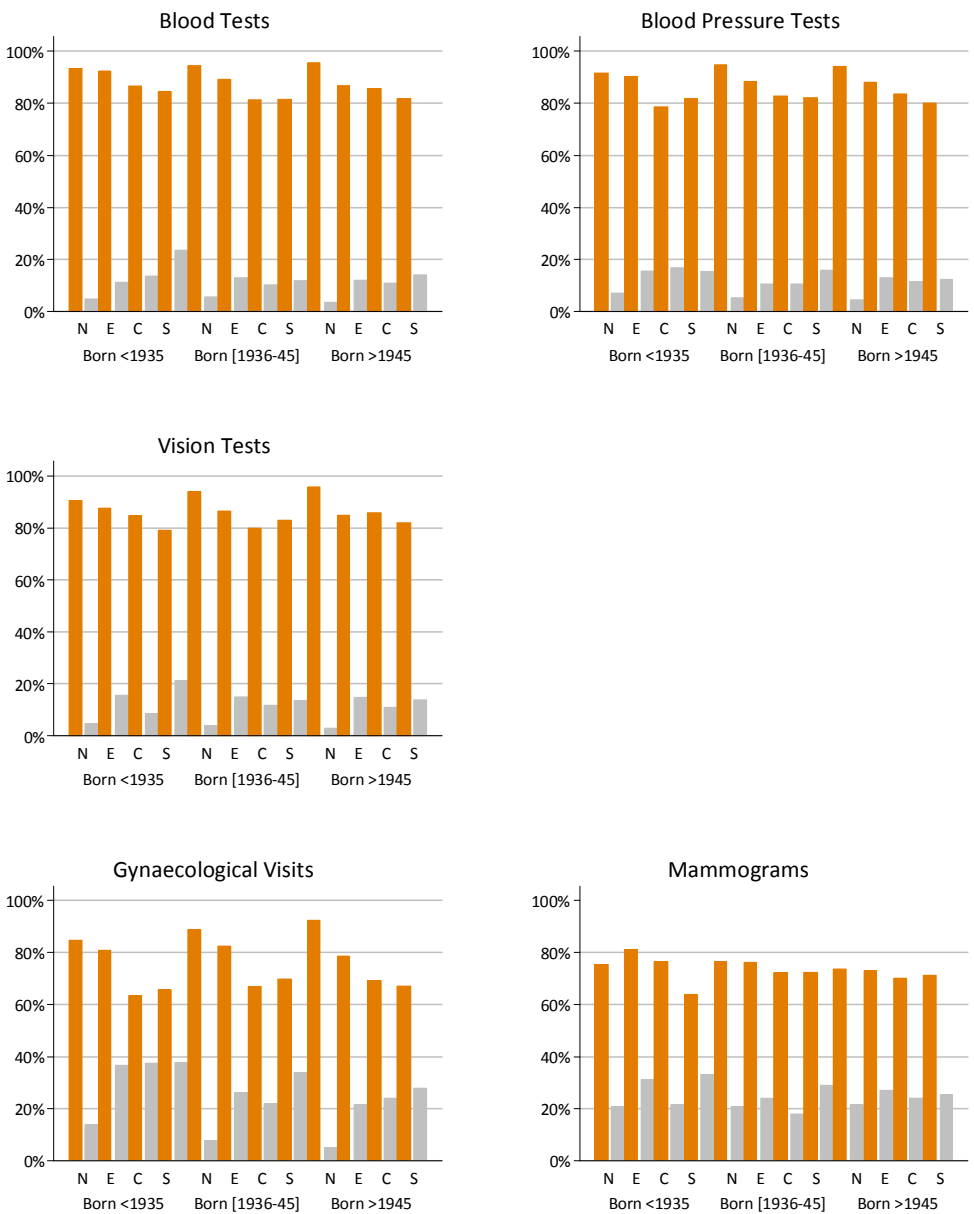

Source: SHARELIFE (2008-2009). Calibrated individual weights used.

Figure 22.3 provides some information on the reasons given for not having regular health care check-ups. "Not considered to be necessary" is the main motive cited to explain why respondents do not use regular health care: more than $80 \%$ of the cases for blood tests, blood pressure, and vision tests, and about $70 \%$ for gynaecological visits and mammograms. While this pattern remains constant across cohorts, there seems to be some variations across euro-regions in particular for gynaecological visits. The results show that about $20 \%$ to $30 \%$ of the population have other reasons for not using regular care: not affordable, not covered by health 
insurance, did not have health insurance, time constraints, not enough information about this type of care, not usual to get this type of care, no place to receive this type of care close to home, etc. Clearly, the importance of these issues depend directly on the health care system design and need to be tackled by appropriate health policies in different countries. Furthermore, the item "Not considered to be necessary" could also capture confounding reasons like being in good health, or having little information about prevention. Note that while the prevalence of regular health check-ups has been increasing at each generation (Figure 22.2), the major reason for not having regular health care has not changed over the three generations. This suggests that there is room for improvement in all countries through public information and education strategies.

\subsection{Determinants of individual healthcare habits}

A general finding in the literature is that privileged people in terms of socioeconomic conditions (education, income, etc.) have a higher propensity to use specialist care. Although this result is well established on cross-sectional and panel data (where care utilisation is investigated over the last year or the last six months), little is known on variations in different types of health services which can have a direct impact on individuals' health and wellbeing. Moreover, health care utilisation over the life-cycle may have a different pattern than health care consumption at a given point. SHARELIFE retrospective data allow for examining consumption habits of individuals over their life course. In order to establish the determinants of regular health care utilisation at the individual level, separate Logit models are run for each dependant variable indicating whether or not individuals ever had regular blood test, blood pressure, vision test, gynaecological visits and mammography. The models control for the following variables at the individual level: general individual characteristics (having children, age and gender), health status, socio-economic conditions (Box 2). Moreover, a series of country and cohort dummies are used for taking into account unobserved heterogeneity across countries and cohorts. Note that in the present analysis individual level observations are nested naturally in cohorts and in countries. Hence we define 39 clusters (C) corresponding to the interaction between countries $(\mathrm{J}=13)$ and cohorts $(\mathrm{T}=3)$.

Results of the logistic regression analysis (Table 22.2) suggest that, all else being equal, men have higher propensity to have regular blood pressure tests than women but lower propensity to have regular vision tests. In addition, controlling for the cohort effects, gynaecological visits and mammograms decrease with age (within cohorts). Age is not significant for other regular health care check-ups. We also note that women with children have significantly higher propensity to have regular gynaecological visits and mammograms, which may suggest that having children has a longer term impact on women's care utilisation habits. 
Table 22.2: $\quad$ Determinants of Regular Health Care Use (Odds-Ratios, Logit Estimates)

\begin{tabular}{|c|c|c|c|c|c|}
\hline Dependent variable & $\begin{array}{r}\text { Blood } \\
\text { pressure }\end{array}$ & $\begin{array}{r}\text { Blood } \\
\text { tests }\end{array}$ & $\begin{array}{r}\text { Vision } \\
\text { tests }\end{array}$ & $\begin{array}{r}\text { Gynec. } \\
\text { visits }\end{array}$ & $\begin{array}{r}\text { Mammo- } \\
\text { grams }\end{array}$ \\
\hline Male & $1.076^{* *}$ & 1.106 & $0.744^{* * *}$ & & \\
\hline Age at Wave 3 & $1.030^{*}$ & 1.026 & 1.016 & $0.954 * *$ & $0.942 *$ \\
\hline With Children & 1.116 & 1.134 & $1.121^{* *}$ & $1.487^{* * *}$ & $1.226 * * *$ \\
\hline Secondary Education & 1.005 & 1.004 & $1.281^{* * *}$ & $1.373^{* * *}$ & $1.357^{* * *}$ \\
\hline Tertiary Education & 0.962 & 1.04 & $1.401 * * *$ & $1.544^{* * *}$ & $1.592^{* * *}$ \\
\hline SRH when child & $1.153^{* * *}$ & $1.149 * * *$ & 0.992 & 0.983 & $1.024^{* *}$ \\
\hline $\begin{array}{l}\text { Periods of ill health | in- } \\
\text { jured }\end{array}$ & $1.396 * * *$ & $1.441^{* * *}$ & $1.210^{* * *}$ & $1.095 * * *$ & $1.127^{* * *}$ \\
\hline SRH at Wave3 & $0.796 * * *$ & $0.817^{* * *}$ & 0.987 & 1.054 & 1.028 \\
\hline 2+ Chronic illnesses & $2.521 * * *$ & $2.597 * * *$ & $1.365^{* * *}$ & $1.111^{* *}$ & $1.260 * * *$ \\
\hline Wear glasses & - & - & $2.544 * * *$ & - & - \\
\hline $\begin{array}{l}\text { Eyes distance } \\
\text { (excellent/v.good) }\end{array}$ & - & - & $0.877^{* * *}$ & - & - \\
\hline $\begin{array}{l}\text { Did you ever work? } \\
\text { (ref. = yes) }\end{array}$ & $1.224 * * *$ & $1.432 * * *$ & $1.246^{* * *}$ & $1.383^{* * *}$ & $1.605^{* * *}$ \\
\hline At work at Wave 3 & 1.007 & $0.951^{* * *}$ & $1.187^{* * *}$ & 1.099 & $0.874^{* *}$ \\
\hline $\begin{array}{l}\text { Periods of financial } \\
\text { hardship }\end{array}$ & 0.932 & 0.984 & 1.006 & $1.048^{*}$ & 0.995 \\
\hline Childhood comfort index & 0.995 & 0.989 & $1.011 * * *$ & $1.063^{* * *}$ & 1.005 \\
\hline Assets Quartile 2 & 1.015 & 1.032 & $1.188^{* * *}$ & $1.111^{* * *}$ & $1.106^{* * *}$ \\
\hline Assets Quartile 3 & 1.062 & $1.097 * * *$ & $1.158^{* * *}$ & $1.218^{* * *}$ & $1.422^{* * *}$ \\
\hline Assets Quartile 4 & $0.974 *$ & $1.084^{* * *}$ & $1.149 * * *$ & $1.263^{* * *}$ & $1.489 * * *$ \\
\hline Obs. & 22251 & 22251 & 22235 & 12128 & 12128 \\
\hline Pseudo $\mathrm{R}^{2}$ & 0.112 & 0.137 & 0.092 & 0.112 & 0.19 \\
\hline
\end{tabular}

Note: ${ }^{* * *} p<1 \%$; ${ }^{* *} p<5 \%$; ${ }^{*}<<10 \%$. Country-cohort fixed effects included but not shown in the table. Categories not shown are reference categories (female, without children, primary education, and assets quartile 1.

The results concerning the impact of health are consistent with the literature: reporting an excellent or very good health status at wave 3 is associated with a lower propensity to have regular blood pressure tests and blood tests, while no impact on the other types of services. On the other hand, having 2 or more chronic illnesses increases the odds of using all types of health services regularly including vision tests. Moreover, having experienced long periods of ill health or having been severely injured appear to increase significantly the propensity to use regular health care. Note that the retrospective self-rated health status in childhood is also asso- 
ciated with regular blood pressure and blood test use, as well as regular mammograms: good child health increases the propensity to have these tests regularly.

As to the impact of socio-economic conditions, we first note that, all else being equal, the impact of socio-economic variables is stronger for vision tests, gynaecological visits, and mammograms which are performed by specialists or depend on referral from specialists. Blood pressure tests, usually carried out regularly by generalists, appear to be distributed more equitably. Second, people with high levels of assets have significantly higher propensity to use regularly all of the health services, except blood pressure tests. Controlling for other socio-economic variables and health status, the odds of having regular gynaecological visits are $26 \%$ higher for people with highest level of assets (4th quartile) compared to those with lowest asset levels. Furthermore, controlling for assets levels, higher levels of economic comfort during childhood also seem to increase the odds of having regular vision tests and gynaecological visits. Third, even after the impact of economic conditions taken into account, the education appears to be a significant determinant of regular care utilisation. All else being equal, the odds of having regular gynaecological visits and mammograms are 50\% higher for women having tertiary education compared to those having only primary education. Finally, having a job or being in the labour market has a mixed effect on regular health care use. On the one hand, having ever worked is the most important determinant of regular care utilisation for all services. The odds of having regular blood test are $43 \%$ higher for people who have had a job one time in their life compared with those who have never worked. The Odds ratios are 1.6 for mammography, 1.4 for gynaecological visits and 1.2 for blood pressure and vision tests. This may reflect the existence of preventive policies introduced through work place regulations but also the insurance status which may depend directly on work status in some countries. On the other hand, controlling for age, having a job at the time of the survey seems to reduce propensity to have regular blood test and mammography. This may suggest the higher time cost of health care for those who are actively in the labour market.

\subsection{Exploring cross-country differences in healthcare habits}

The results from Table 22.2 show that, adjusted for the individual differences in health and living conditions, there is still significant heterogeneity in regular care utilisation between countries and cohorts. For example, the Logit coefficients presented in Figure 22.4 give the propensity of using regular blood tests by country and by cohort, after controlling for individual characteristics of respondents. They indicate that there is a north-south gradient in the propensity to have regular blood tests. These findings corroborate previous findings from Figure 22.1, and allow disentangling country effects from cohort effects.

Figure 22.4: Propensity to have regular blood tests, by cohort and country 


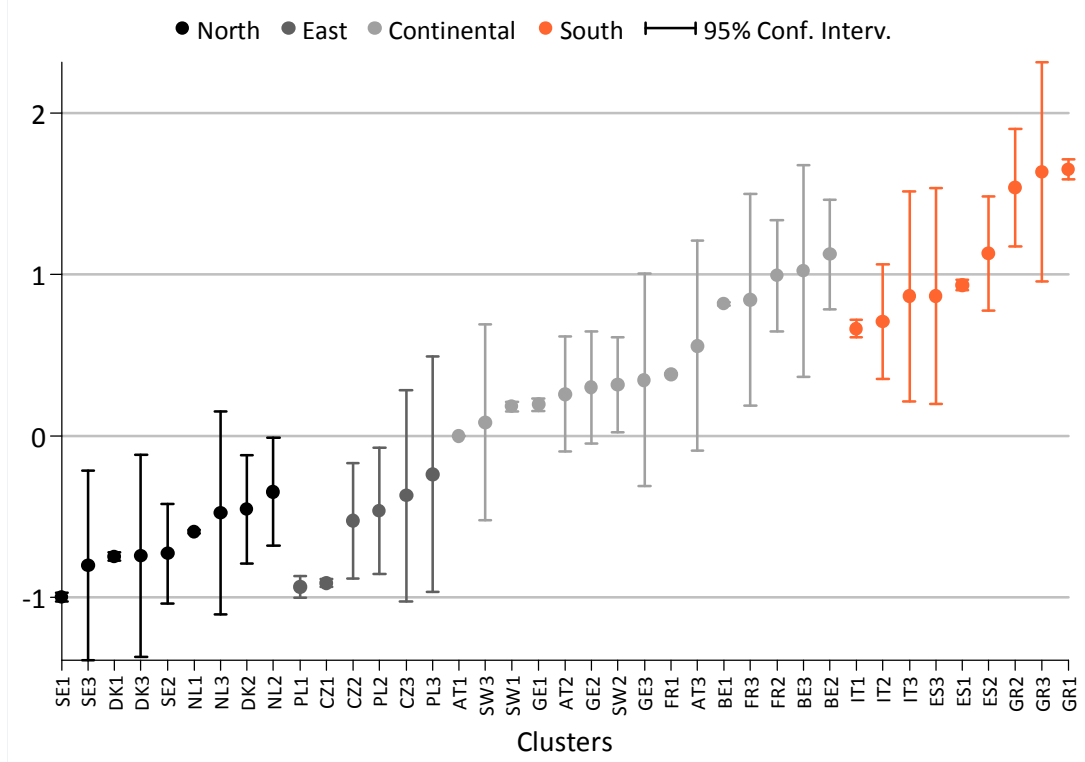

Note: Fixed effects controlled for a set of individual variables.

Reference is AT1 (Austria, Cohort 1: Before 1935).

In order to explain these differences in regular care use across countries and cohorts, we estimated panel data models with time fixed effects. The coefficients of country/cohort clusters (fixed effects) for each type of regular heath care are used as a new dependant variable to be regressed on a set of country-cohort level context variables. Cohort 1 for Poland and the Czech Republic were removed from this analysis because some context variables were not available for the period 1975-1985 for these two clusters.

In these models, we test for the impact of general economic development of a country (GDP) and the resources devoted to health care system on health care utilisation patterns of country/cohorts. As presented before we have three variables for measuring overall health system resources. These health care variables are introduced one by one in the equations together with the GDP. This probably captures better the general economic and health care conditions for each cohort in different countries. It also allows "isolating" the effect of health care policies on regular care use from the confounding influence of economic growth. For sake of simplicity, only the significant results are displayed in Table 22.3 (Comprehensive results are available from the authors upon request). 
Table 22.3: Determinants of cross-country differences in regular health care use (odds ratios)

\begin{tabular}{|c|c|c|c|c|c|}
\hline $\begin{array}{l}\text { Dep. var: coeffs. of clusters } \\
\text { from logit models: }\end{array}$ & $\begin{array}{r}\text { Blood } \\
\text { pressure }\end{array}$ & $\begin{array}{r}\text { Blood } \\
\text { tests }\end{array}$ & $\begin{array}{r}\text { Vision } \\
\text { tests }\end{array}$ & $\begin{array}{l}\text { Gynec. } \\
\text { visits }\end{array}$ & $\begin{array}{r}\text { Mammo- } \\
\text { grams }\end{array}$ \\
\hline \multicolumn{6}{|l|}{ Model 1} \\
\hline $\begin{array}{l}\text { GDP per capita, Mean average } \\
\text { annual growth rate (over } 10 \\
\text { years) }\end{array}$ & $0.810^{*}$ & 0.84 & 0.84 & 0.842 & 0.993 \\
\hline $\begin{array}{l}\text { THE per capita, Mean average } \\
\text { annual growth rate (over } 10 \\
\text { years) }\end{array}$ & $1.265^{* *}$ & $1.244^{*}$ & $1.210 * *$ & 1.038 & 1.069 \\
\hline \multicolumn{6}{|l|}{ Model 2} \\
\hline $\begin{array}{l}\text { GDP per capita, Total growth } \\
\text { rate (10 years) }\end{array}$ & 0.982 & 0.985 & 0.986 & 0.986 & 0.997 \\
\hline $\begin{array}{l}\text { THE per capita, Total growth } \\
\text { rate (10 years) }\end{array}$ & $1.017^{* *}$ & $1.016^{*}$ & $1.014^{* *}$ & 1.003 & 1.007 \\
\hline \multicolumn{6}{|l|}{ Model 3} \\
\hline $\begin{array}{l}\text { GDP per capita, Average (over } \\
10 \text { years) }\end{array}$ & $0.999 * * *$ & $0.999 * * *$ & $0.999 * * *$ & 1.000 & 1.000 \\
\hline $\begin{array}{l}\text { Practising physicians - Density } \\
\text { /1000 pop. Average (over } 10 \\
\text { years) }\end{array}$ & $1.400 * * *$ & $1.525^{* * *}$ & $1.241^{*}$ & $1.331^{*}$ & 1.053 \\
\hline \multicolumn{6}{|l|}{ Time Fixed Effects Model } \\
\hline \multicolumn{6}{|l|}{ Model 4} \\
\hline $\begin{array}{l}\text { GDP per capita, Mean average } \\
\text { annual growth rate (over } 10 \\
\text { years) }\end{array}$ & $0.784^{*}$ & 0.817 & 0.807 & 0.844 & 1.037 \\
\hline $\begin{array}{l}\text { THE per capita, Mean average } \\
\text { annual growth rate (over } 10 \\
\text { years) }\end{array}$ & $1.291 * * *$ & $1.263^{*}$ & $1.230 * *$ & 1.021 & 1.059 \\
\hline \multicolumn{6}{|l|}{ Model 5} \\
\hline $\begin{array}{l}\text { GDP per capita, Total growth } \\
\text { rate (10 years) }\end{array}$ & $0.979 *$ & 0.982 & 0.982 & 0.986 & 1 \\
\hline $\begin{array}{l}\text { THE per capita, Total growth } \\
\text { rate (10 years) }\end{array}$ & $1.019 * *$ & $1.018^{*}$ & $1.015^{* *}$ & 1.002 & 1.006 \\
\hline \multicolumn{6}{|l|}{ Model 6} \\
\hline $\begin{array}{l}\text { GDP per capita, Average (over } \\
10 \text { years) }\end{array}$ & $0.999 * * *$ & $0.999 * * *$ & $0.999 * * *$ & 1.000 & 1.000 \\
\hline $\begin{array}{l}\text { Practising physicians - Density } \\
\text { /1000 pop. Average (over } 10 \\
\text { years) }\end{array}$ & $1.962^{* * *}$ & $2.160^{* * *}$ & 1.289 & $1.719 * *$ & 1.282 \\
\hline
\end{tabular}


The results suggest that physician density has a significant impact on the utilisation of most health services. The propensity to have regular blood pressure, blood tests, vision tests, gynaecological visits is significantly higher in country/cohorts where the number of physicians per capita is higher. However, concerning mammography, there is no significant impact of physician density on their regular utilisation. This is not surprising since in most countries, breast cancer screening is also carried out within specific targeted programmes mobilising different resources, while all the other services require a physician contact/visit. In addition, controlling for GDP growth, individuals who were in countries and cohorts where the average growth rate in health expenditure was higher, have a higher propensity to use regular health check-ups for blood pressure, blood and vision tests. The health expenditure growth (in real terms) reflects probably the overall investment effort in healthcare by period and by country and may indicate improvement in availability (easier access) of services. It is interesting to see that controlling for health care resources, GDP growth does not have any significant impact on individuals' care consumption habits. There is even a small negative impact on the use of blood pressure tests, which may suggest that during the periods of rapid economic growth, time cost for healthcare is higher and less attention is paid to health (Ruhm, 1996). When time invariant effects are taken into account (cohort effects), cross-country differences in Europe in terms of the prevalence of regular health care utilisation is partly explained by national strategies regarding the provision of practising physicians and overall investment in health care.

\subsection{Conclusion}

This study provides some new evidence on the variations of health care utilisation habits of different cohorts in 13 European countries. We found that while there is a general shift toward more regular and preventive care utilisation in all countries; there are still significant differences between countries and cohorts.

Our results confirm that there are significant social inequalities in the life time regular utilisation of health care services allowing for early detection and prevention, after correcting for differences in the need for care over the life-cycle. Individuals with higher levels of education and assets have a higher propensity to have regular use of blood tests, vision tests, gynaecological visits, and mammograms. The impact of education is significant even after controlling for income and occupation. We also find that social inequalities are stronger for services provided by specialists.

There is also evidence that, once the individual effects have been isolated, cross-cohort and country differences in the prevalence of regular care use are partly associated with national health policies. Controlling for GDP growth, physician density also appears to be a significant determinant of regular utilisation of 
all health services except for mammography. Moreover, countries and cohorts which have experienced higher growth rates of total health expenditures have higher prevalence of regular blood pressure tests and regular vision tests. In contrast, the impact of overall economic growth on health care utilisation habits appears to be insignificant if not negative.

These results suggest that there is significant room for public health policies for reducing disparities in regular use of health services within and across European countries. Health promotion and education can play an essential role for assuring equal and timely treatment of diseases within and across countries. Moreover, strengthening primary care provision appears to be critical for improving health systems' ability to provide and develop services in a timely manner.

\section{References}

Franco E.L, Duarte-Franco E, Rohan TE, et al. (2002). Evidence-based policy recommendations on cancer screening and prevention. Cancer Detect Prev, 2002. Vol. 26(5), pp. 350-361.

Gohdes DM, Balamurugan A, Larsen BA, et al. (2005). Age-related eye diseases: an emerging challenge for public health professionals. Prev Chronic Dis, 2005. Vol. 2(3), p. A17.

Hanratty B, Zhang T, Whitehead M. (2007). How close have universal health systems come to achieving equity in use of curative services? A systematic review". International Journal of Health Services, Vol. 37(1), pp. 89-109.

Klemi PJ, Parvinen I, Pylkkanen L, et al. (2003). Significant improvement in breast cancer survival through population-based mammography screening. Breast, 2003. Vol. 12(5), pp. 308313.

Mandel JS, Church TR, Bond JH, et al. 2000, The effect of fecal occult-blood screening on the incidence of colorectal cancer. N Engl J Med, 2000. Vol. 343(22), pp. 1603-1607.

Ruhm C.J., (1996), Are recessions good for your health? National Bureau of Economic Research (NBER), Working Paper, no. 5570.

Van Doorslaer E., Masseria C. and the OECD Health Equity Research Group Members (2004). Income-Related Inequality in the Use of Medical Care in 21 OECD Countries. OECD Health Working Paper, 14.

Van Doorslaer E., Masseria C., Koolman X. for the OECD Health Equity Research Group (2006). Inequalities in access to medical care by income in developed countries. Canadian Medical Journal, Vol. 174(2). doi:10.1503/cmaj.050584.

WHO (2002). Integrating prevention into health care. Fact Sheet. No. 172. Geneva. 